\title{
HOT WATER TREATMENT OF LIGHTBROWN APPLE MOTH EGGS ON APPLES AND NECTARINES
}

\author{
V.M. JONES and B.C. WADDELL \\ The Horticulture and Food Research Institute of New Zealand Ltd., \\ Private Bag 92 169, Auckland, New Zealand
}

\begin{abstract}
Lightbrown apple moth (LBAM, Epiphyas postvittana (Walker)) is a pest of quarantine concern on New Zealand apple and summerfruit exports. The potential for using hot water for postharvest control of this pest is now being evaluated. The tolerance of mid-aged eggs of LBAM to hot water treatments was compared when the eggs were allowed to infest onto apples or nectarines. Mortality responses of mid-aged eggs exposed to hot water at $45-57^{\circ} \mathrm{C}$ were similar whether the eggs were infesting apples or nectarines. As temperature increased, the time required to achieve $99 \%$ mortality $\left(\mathrm{LT}_{99}\right)$ decreased from 26.6 minutes at $45^{\circ} \mathrm{C}$ to 0.6 minutes at $57^{\circ} \mathrm{C}$ for apples, and from 29.3 to 0.5 minutes for nectarines.
\end{abstract}

Keywords: lightbrown apple moth, hot water, disinfestation

\section{INTRODUCTION}

Lightbrown apple moth (LBAM, Epiphyas postvittana (Walker)) is a pest of quarantine concern on New Zealand apple and summerfruit exports. Interception of the pest can result in rejection of large volumes of produce destined for the USA. At present, postharvest control of LBAM can only be assured by fumigation with methyl bromide. Alternative non-chemical treatments are now being sought for postharvest insect control. Heat treatment is one alternative which has been implemented to control potential infestations of fruit flies on several tropical crops (Armstrong et al. 1989; Waddell et al. 1993), and is now being considered for temperate fruits.

The first step in evaluating the potential usefulness of hot water to disinfest apples and summerfruit of leafrollers involved comparing responses of the various lifestages of the pests of concern in the absence of the host fruits ('off fruit'). LBAM was identified as the leafroller most tolerant to hot water, and mid-aged eggs of LBAM as the most tolerant egg age of the pest (Jones et al. 1995).

In this paper we report on the mortality responses of LBAM eggs infested onto the host fruits ('on fruit'), given that the 'heat sink' effect of the fruit (resulting in a correspondingly longer time to heat the insects) could influence the $\mathrm{LT}_{99}$ (time required to achieve $99 \%$ mortality). We compared responses of eggs infesting both apples and nectarines, since their different heating characteristics might also confer different insect mortalities.

\section{METHODS}

All experiments were carried out in a 38-litre circulating waterbath (Grant, Model W38-ZD), accurate to $\pm 0.1^{\circ} \mathrm{C}$ of the temperature nominated for each trial. A separate bath, used for holding the wet controls, was maintained at $20 \pm 0.5^{\circ} \mathrm{C}$. The treatment temperature was verified before the start of each trial using a digital reference thermometer (RT 200, Industrial Research Limited, New Zealand), certified for accuracy by the Measurements Standards Laboratory of New Zealand, Wellington. A 16-channel data logger (Grant Squirrel, Model SQ32-8U/8U), accurate to $\pm 0.1^{\circ} \mathrm{C}$, was used to record the temperature of both the water and the fruit pulp at 10 second intervals. Temperature data were transferred from the data logger using the Grant Instruments Squirrel Analysis Program and analysed using the Borland Quattro Pro Spreadsheet.

Proc. 49th N.Z. Plant Protection Conf. 1996: 71-74 
'Fantasia' nectarines were obtained from the HortResearch Clyde Research Centre, Central Otago, and 'Royal Gala' apples from a Hawkes Bay commercial orchard. The fruit were kept free of insecticidal sprays for ten weeks prior to harvest, but received regular fungicidal sprays. All individual fruit weighed 150-170 g. Fruit were kept in standard coolstorage $\left(0.5^{\circ} \mathrm{C}\right)$ and were transferred to $20^{\circ} \mathrm{C}$ for 24 hours before infestation with the insects.

Insects were sourced from laboratory colonies maintained at $20^{\circ} \mathrm{C}, 60 \% \mathrm{RH}$ and a photoperiod of 16:8 (L:D) hours at HortResearch, Auckland. Thirty pairs of adult moths were supplied in each of three gauze bag oviposition cages. Ten fruit (apples or nectarines) were placed inside each cage and removed after 24 hours. The egginfested fruit were held at $20^{\circ} \mathrm{C}$ for a further 3 days (mid-aged eggs).

Three infested fruit were placed into each of 10 cylindrical plastic netting baskets (comprising one trial), which were assigned to either 'treatment' (eight baskets) or wet control (two baskets). Lead weights were attached to the ends of each basket to ensure submersion. Three treatment baskets were simultaneously immersed into the waterbath (maintaining a constant load of nine fruit), and one removed after different time intervals ( 15 seconds to 36 minutes depending on the temperature), in order to achieve a range of mortalities. As each sample was removed from the waterbath it was transferred immediately to the $20^{\circ} \mathrm{C}$ bath for 2 minutes, in order to stop the heating process.

Two 'sets' of three samples were treated in this manner, while the remaining two treatment baskets, representing the longest sample durations for that trial, were placed in the waterbath with one 'probe' and two 'filler' fruit (total nine fruit). Three probes, one 'surface' (inserted just under the surface of the fruit), one 'flesh' (placed $1 \mathrm{~cm}$ into the fruit) and one either 'core' (apples) or 'stone' (nectarines) were sealed into the probe fruit using paraffin wax. A 'water' probe measured the temperature of the water in the baths. The water probe and probe fruit were transferred from the treatment to the hydrocooling bath along with the last treatment basket for that trial.

Wet control fruits were held in the $20^{\circ} \mathrm{C}$ bath for the longest duration tested at each temperature.

Fruit from each basket were left to dry for approximately 30 minutes, then stored in a plastic container with a perforated lid which secured a fine fabric liner, allowing air exchange, and held at $20^{\circ} \mathrm{C}, 60 \% \mathrm{RH}$ and 16:8 (L:D). Mortality was assessed 10 days after treatment by counting the number of live ('hatched') and dead ('unhatched') eggs.

A total of 10 trials was conducted on apples at $45^{\circ} \mathrm{C}(2$ replicates, $\mathrm{n}=14388), 49^{\circ} \mathrm{C}$ $(2, \mathrm{n}=10284), 53^{\circ} \mathrm{C}(3, \mathrm{n}=20012)$ and $57^{\circ} \mathrm{C}(3, \mathrm{n}=13084)$, and eight on nectarines at $45^{\circ} \mathrm{C}(2, \mathrm{n}=10684), 49^{\circ} \mathrm{C}(2, \mathrm{n}=14831), 53^{\circ} \mathrm{C}(2, \mathrm{n}=17516)$ and $57^{\circ} \mathrm{C}(2, \mathrm{n}=8238)$.

A complementary log-log transformation was applied to the data in order to determine the mortality response versus exposure time at a particular temperature (Maindonald 1988; Preisler and Robertson 1989). Control mortality was excluded when fitting the model to the data, but included in the subsequent determination of the $\mathrm{LT}_{99}$ (i.e. estimated time for $99 \%$ mortality) using the Maximum Likelihood Program (Ross 1980). From the individual $\mathrm{LT}_{99} \mathrm{~S}$ thus calculated, a mean and SEM were calculated for each temperature. For each value predicted by the model, $95 \%$ confidence limits were calculated and used to examine differences in $\mathrm{LT}_{99}$. A comparison based on whether or not these confidence limits overlap is equivalent to a significance test with a P-value of approximately 0.01. All differences are reported to this level of significance.

\section{RESULTS AND DISCUSSION}

Representative thermal profiles for apples and nectarines at $49^{\circ} \mathrm{C}$ indicate that heating at the fruit surface (where the eggs were located) was virtually identical (Fig. 1). In both cases, the surface temperature at the end of the heat treatment was several degrees below the target, which shows the temperature 'lag' between target $\left(49^{\circ} \mathrm{C}\right)$ and fruit $\left(44-45^{\circ} \mathrm{C}\right)$ temperatures. Higher temperatures were recorded for nectarines than for apples in both flesh (by up to $1.5^{\circ} \mathrm{C}$ ) and core/stone (by up to $5.5^{\circ} \mathrm{C}$ ) locations.

The $\mathrm{LT}_{99}$ for mid-aged eggs of LBAM infesting apples decreased with increasing temperature from 26.6 minutes at $45^{\circ} \mathrm{C}$ to 0.6 minutes at $57^{\circ} \mathrm{C}$ and from 29.3 to 0.5 minutes for nectarines (Table 1; Fig. 2). There were no differences between the $\mathrm{LT}_{99} \mathrm{~S}$ 


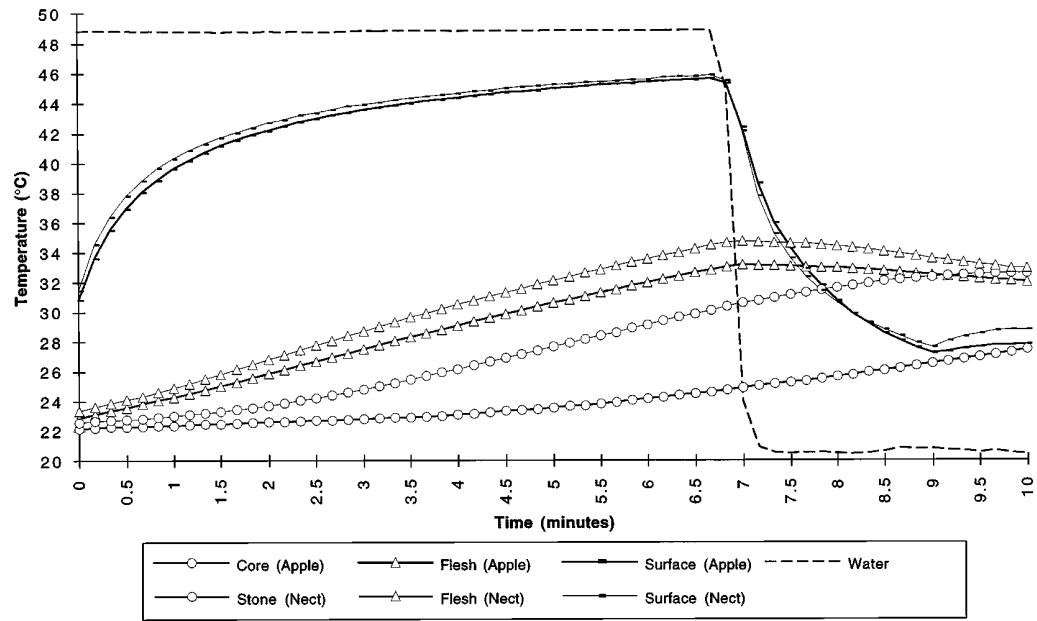

FIGURE 1: Temperature profile for apples and nectarines exposed to hot water at $49^{\circ} \mathrm{C}$ for 7 minutes followed by hydrocooling at $20^{\circ} \mathrm{C}$ for 2 minutes.

for eggs infesting apples or nectarines, probably largely because their heating profiles were so similar.

$\mathrm{LT}_{99} \mathrm{~S}$ at $45^{\circ} \mathrm{C}$ for eggs treated on apples (26.6 minutes) and nectarines (29.3 minutes) were considerably longer than the $\mathrm{LT}_{99}$ observed for eggs treated on plastic sheets i.e. 'off fruit' (16 minutes) (Jones et al. 1995). The greater heat tolerance of pests infesting fruit compared with 'off fruit' trials is typical in disinfestation research, as the fruit temperature lag results in a correspondingly longer time to kill the pests.

Since mortalities are the same for LBAM eggs on apples or nectarines, information gained using eggs infesting one crop need not be duplicated on the other. The mortality responses of larval instars of LBAM, which might be found inside the fruit where temperature differences are far greater than at the fruit surface, would be of interest in a further study.

TABLE 1: Estimated times in minutes for $99 \%$ mortality $\left(\right.$ LT $\left._{99}\right)$ of LBAM eggs infesting apples and nectarines following exposure to hot water at $45-57^{\circ} \mathrm{C}$.

\begin{tabular}{|c|c|c|c|c|}
\hline & & Tem & $\left.{ }^{\circ} \mathrm{C}\right)$ & \\
\hline & 45 & 49 & 53 & 57 \\
\hline On apples & 27.2 & 5.4 & 1.7 & 0.7 \\
\hline & 26.1 & 5.1 & 1.7 & 0.4 \\
\hline & & & 1.7 & 0.6 \\
\hline Mean $^{1}$ & 26.6 & 5.3 & 1.7 & 0.6 \\
\hline SEM & 0.55 & 0.14 & 0.02 & 0.08 \\
\hline On nectarines & 30.6 & 7.0 & 1.8 & 0.5 \\
\hline & 28.1 & 6.1 & 1.9 & 0.6 \\
\hline Mean $^{1}$ & 29.3 & 6.5 & 1.8 & 0.5 \\
\hline SEM & 1.29 & 0.47 & 0.07 & 0.05 \\
\hline
\end{tabular}

${ }^{1}$ Means calculated from $\log \left(\mathrm{LT}_{99}\right)$ values and back-transformed to give the values shown. 


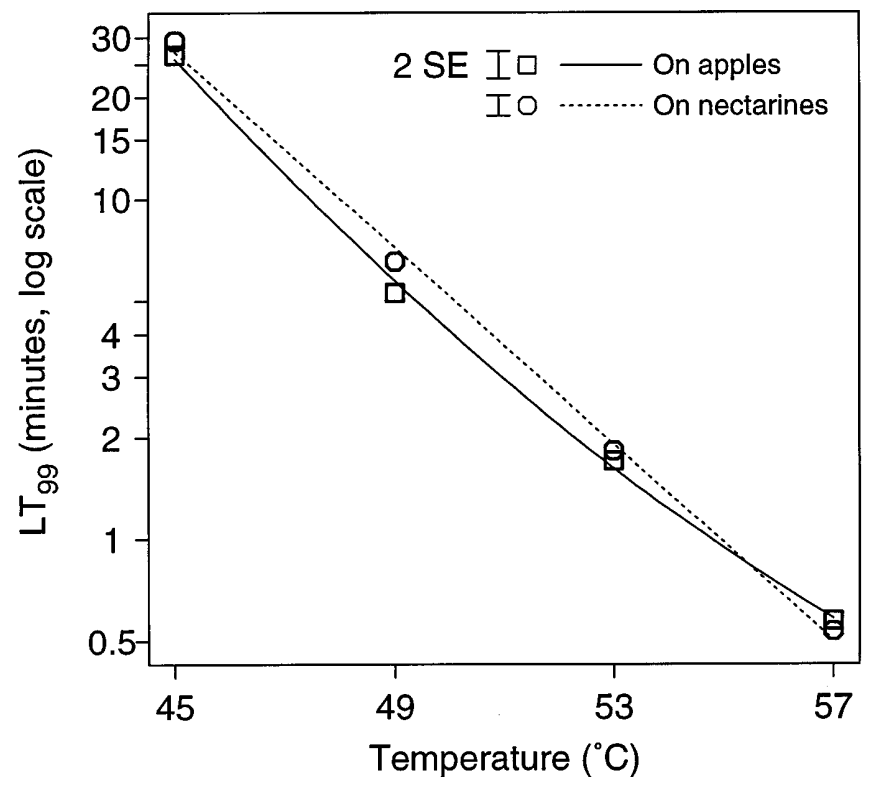

FIGURE 2: Estimated times in minutes for $99 \%$ mortality (LT 99 $_{\text {) }}$ of LBAM eggs infesting apples and nectarines following exposure to hot water at $45-57^{\circ} \mathrm{C}$. The error bars in the legend are the rms of the Ses at all points on the respective lines. Equations where $t=$ temperature: on apples $\log \mathrm{y}=37.284$ [SE 6.864] -1.104 [SE 0.270]t +0.008 [SE $0.003] t^{2}$; on nectarines $\log y=18.253$ [SE 0.395] - 0.332 [SE 0.008]t.

\section{ACKNOWLEDGEMENTS}

We wish to thank Mr David Lynch for the supply of nectarines; Ms Anne Barrington and Insect Rearing staff for the supply of insects; Mr John Maindonald and Mr Patrick Connelly for statistical analysis of the data; and Mr Dave Rogers and Dr Michael Lay-Yee for comments on the manuscript.

\section{REFERENCES}

Armstrong, J.W., Hansen, J.D., Hu, B.K.S. and Brown, S.A., 1989. High-temperature, forced-air quarantine treatment for papayas infested with tephritid fruit flies (Diptera: Tephritidae). J. Econ. Entomol. 82(6): 1667-1674.

Jones, V.M., Waddell, B.C. and Maindonald, J.H., 1995. Comparative mortality responses of three tortricid (Lepidoptera) species to hot water. J. Econ. Entomol. 88(5): 1356-1360.

Maindonald, J.H., 1988. Fitting Complementary Log-Log Response Lines. Report prepared for the Ministry of Agriculture, Forestry and Fisheries, Japan. 11pp.

Preisler, H.K. and Robertson, J.L., 1989. Analysis of time-dose mortality data. J. Econ. Entomol. 82: 1534-1542.

Ross, G.J.S., 1980. MLP 3.06. Maximum Likelihood Program. Lawes Agricultural Trust, Rothamsted Experiment Station, England.

Waddell, B.C., Clare, G.K., Maindonald, J.H. and Petry, R.J., 1993. Postharvest Disinfestation of Bactrocera melanotus and B. xanthodes in the Cook Islands: Report 3. HortResearch Client Report No. 93/270. 43pp. 